\title{
Menstrual fluctuation in the symptoms of panic anxiety
}

\author{
Oliver G. Cameron, Dorothy Kuttesch, Kathleen McPhee and George C. Curtis \\ Depurtment of Psychiatry, University of Michigan Medical Center, Ann Arbor, MI 48109, U.S.A.
}

(Received 14 January 1988)

(Accepted 18 March 1988)

\begin{abstract}
Summary
Ten women with DSM-III-defined panic attacks (five with and five without agoraphobia) had symptom severity rated daily, weekly, and retrospectively through one full menstrual cycle. Substantial fluctuations in retrospective ratings of severity were observed, with the premenstrual week being rated as most severe. Daily and weekly ratings showed much smaller fluctuations in the predicted direction. Possible reasons for this outcome are considered.
\end{abstract}

Key words: Panic anxiety; Menstrual fluctuation

\section{Introduction}

Many women report both physical and psychological symptoms associated with the premenstruum, as acknowledged by the terms 'premenstrual tension or syndrome' (e.g., Frank, 1931; Dalton, 1964; Steiner et al., 1980; Rubinow and Roy-Byrne, 1984) or 'late luteal phase dysphoric disorder' (American Psychiatric Association, 1987). Among the psychological symptoms in otherwise normal women reported to be greater premenstrually is anxiety (e.g., Golub, 1976; Veith et al., 1984), although others have not observed a reliable premenstrual increase in anxiely (c.g.. Lahmeyer et al., 1982; Van Den Akker and Steptoe, 1985). Retrospective studies of women with

\footnotetext{
Address for correspondence: Oliver G. Cameron, M.D., Ph.D., Department of Psychiatry, University of Michigan Medical Center, 900 Wall Street, Ann Arbor, MI 48109, U.S.A.
}

anxiety disorders have also reported a premenstrual exacerbation of anxiety symptoms (Breier et al., 1986; Cameron et al., 1986). The purpose of the present study was to evaluate prospectively menstruating women with the anxiety disorder, panic attacks with or without agoraphobia (American Psychiatric Association, 1980, 1987), in order to determine if the retrospective reports of premenstrual increases in anxiety severity could be verified prospectively.

\section{Method}

\section{Subjects}

Ten menstruating women who presented consecutively to the University of Michigan Anxiety Disorders Program were studied. All were evaluated by an experienced clinician, using both the Structured Interview for DSM-III (Spitzer and Williams, 1983) and a semi-structured clinical interview. By coincidence, five reached diagnostic 
criteria for panic disorder, as defined by DSM-III, and five reached criteria for agoraphobia with panic attacks. Age of the subjects, mean age of onset of the disorder, and menstrual cycle length (days) for the cycle studied were recorded. No subject reached criteria for any other DSM-III or DSM-III-R Axis I disorder at the time of study, all reported being medically in good health, and all were drug-free for at least 1 week before and throughout the study; eight had received prior drug treatment.

\section{Procedure}

All subjects were studied for at least one full menstrual cycle from day of menstrual onset to day prior to day of onset of the next menstrual period. For each subject, the study was started at the time of enrollment, irrespective of the point in the cycle, but continued at least until completion of one full cycle (day of onset to last day of that cycle); thus, data were always available for one full cycle. Subjects were told that the purpose of the study was to evaluate the longitudinal course of their symptoms; no mention was made of any interest in the relationship of symptoms to the menstrual cycle. However, among many data items collected. day of onset of menstrual flow was determined for each subject so that coincidence of symptoms and cycle could be determined. At the end of each day during the study, each subject recorded separately the number of (a) full unexpected, (b) full situational, (c) limited unexpected, and (d) limited situational panic attacks (American Psychiatric Association, 1987). Each attack was also rated for duration (in minutes) and severity $(0-9)$. Additionally, the severity $(0-9)$ for all criterion symptoms listed in DSM-III-R for all panic attacks on that day were recorded. Finally, a list of 25 symptoms associated with panic, generalized anxiety disorder, and/or 'late luteal phase dysphoric disorder', as defined in DSM-III-R, were also rated $(0-9)$. For all ' $0-9$ ' ratings, $0=$ 'none'. and $9=$ 'most ever'.

In addition to the daily rating, patients were seen every week by the same clinician; further self-ratings and clinician rating scales were completed at these times. These included: (a) the same ratings of the four types of panic attacks as described above, done jointly by clinician and pa- tients with the average intensity of all attacks $(0-9)$; (b) the percentage of time spent feeling anxious between attacks: (c) the same 25 symptoms as rated daily by the patients: (d) the Sheehan (1986) and Hamilton (1959) anxiety scales, and the SCL-90-R (Derogatis, 1983) (all rated $0 \div$ none to $4=$ severe); (e) the Sheehan disability scale (Sheehan, 1986); (f) and the Marks-Sheehan fear (0-9) and avoidance $(0-4)$ scales (Marks and Mathews, 1979: Shechan, 1986).

After completion of the daily and weekly ratings, before description of the purpose of the study, all patients rated, retrospectively for each week, the average severity (0-9) of panic attacks, agoraphobic symptoms, and 'premenstrual symptoms'. Additionally, the same 25 symptoms were rated again. After completion of the retrospective ratings, patients were 'debriefed' concerning their understanding of the purpose of the study. and their 'thoughts' on any possible reasons for the outcome.

\section{Data analysis}

Statistical tests used included the Sign test, paired $t$-tests, and profile analyses; profile analysis is a multivariate statistical test analogous to repeated measures ANOVA with one betweengroup and one within-group variable (Harris, 1975). All significance tests were performed at $P<0.05$; no adjustment for number of tests was used. Because the durations of the menstrual cycles studied were not the same for each subject and often did not equal 28 days, data analysis for the prospective ratings actually involved 21 days. These were the seven consecutive days starting with the first day of the menstrual period (perimenstrual), the seven days immediately preceding the perimenstrual time (premenstrual), and the seven days closest to mid-cycle. Scores are reported (Table 1) as means of these 7-day periods. Shorter periods were also used for some of these prospective calculations; conclusions did not differ.

\section{Results}

Age of the subjects was $34.3 \pm 7.1$ years (mean \pm standard deviation), and age of onset of the disorder was $22.6 \pm 4.8$ years. The mean menstrual 
cycle length was $30.1 \pm 6.7$ days, which is normal (World Health Organization, 1983). Four had been diagnosed previously as having "premenstrual syndrome'. Six were married, three divorced, and one never married. Across the menstrual cycle average numbers of panic attacks per week were: 1.60 full unexpected; 0.73 limited unexpected; 1.20 full situational; and 2.97 limited situational.

Several individual symptoms showed significant fluctuations across the menstrual cycle when rated retrospectively; they were 'depressed' $(P<0.008)$, 'change of appetite' $(P<0.02)$, 'moodiness' $(P<$ $0.003)$, 'loss of interest' $(P<0.05)$, 'feeling keyed up' $(P<0.02)$, 'irritability' $(P<0.03)$, and 'physical discomfort' $(P<0.007)$ (Table 1). All of these symptoms showed highest scores during the pre- menstrual and/or perimenstrual weeks. In contrast to these retrospective ratings, among these 25 symptoms, only 'loss of interest' showed a significant fluctuation during the weekly ratings $(P<$ $0.02)$, and only 'physical distress' $(P<0.04)$ and 'muscle tension' $(P<0.04)$ showed significant fluctuations in the prospective ratings. Additionally, the mean score for the 25 symptoms showed a significant fluctuation for the retrospective $(P<$ 0.03 ) but not for the weekly or prospective ratings; this was due primarily to higher retrospective mean scores in the pre/perimenstruum. In contrast, there was a significantly larger number of symptoms that were greater premenstrually than in the mid-cycle weeks $(20 / 25$, by the Sign test. $P<0.005$ ). Thus, based on the same set of symp-

TABLE 1

AVFRAGE SCORES OF ALL TEN SUBJECTS ON RETROSPECTIVELY, WEEKLY, AND PROSPECTIVELY RATED SYMPTOMS

\begin{tabular}{|c|c|c|c|c|c|c|c|c|c|c|c|}
\hline & \multicolumn{4}{|c|}{ Retrospective } & \multicolumn{4}{|c|}{ Weekly } & \multicolumn{3}{|c|}{ Prospective } \\
\hline & 1 & 2 & 3 & 4 & 1 & 2 & 3 & 4 & 1 & 2 & 3.4 \\
\hline Trembling & 5.70 & 4.80 & 3.60 & 3.70 & 4.30 & 3.70 & 3.30 & 4.40 & 2.67 & 2.51 & 2.16 \\
\hline Muscles tense & 6.90 & 5.90 & 2.00 & 2.10 & 4.20 & 3.90 & 2.90 & 2.90 & 3.00 & 3.44 & 2.47 \\
\hline Restless & 5.20 & 2.70 & 2.30 & 2.50 & 3.50 & 3.50 & 3.70 & 3.50 & 2.37 & 2.59 & 2.61 \\
\hline Low energy & 5.40 & 3.70 & 1.30 & 1.80 & 3.50 & 3.90 & 3.00 & 2.50 & 2.59 & 2.74 & 1.73 \\
\hline Depressed & 7.10 & 4.90 & 2.30 & 2.80 & 4.10 & 4.50 & 3,20 & 3.20 & 2.51 & 2.67 & 2.21 \\
\hline Change of appetite & 6.50 & 1.70 & 0.80 & 1.30 & 3.20 & 1.40 & 1.60 & 2.80 & 1.66 & 0.91 & 1.21 \\
\hline Worry & 4.80 & 3.20 & 2.20 & 2.40 & 3.20 & 3.10 & 2.70 & 2.70 & 1.04 & 1.40 & 1.40 \\
\hline Moodiness & 7.90 & 5.20 & 2.20 & 2.70 & 4.00 & 3.60 & 3.20 & 3.30 & 2.36 & 2.26 & 1.57 \\
\hline Lost interest & 3.90 & 2.20 & 1.10 & 1.20 & 3.20 & 3.60 & 1.20 & 2.30 & 1.61 & 1.14 & 1.21 \\
\hline Trouble sleeping & 2.70 & 3.10 & 1.80 & 1.80 & 3.80 & 3.10 & 2.50 & 3.00 & 1.99 & 1.31 & 1.21 \\
\hline Increased sleeping & 1.40 & 0.70 & 0.00 & 0.10 & 0.70 & 0.00 & 0.40 & 0.90 & 0.41 & 0.20 & 0.29 \\
\hline Shortness of breath & 4.80 & 3.50 & 2.80 & 2.80 & 3.60 & 2.70 & 4.00 & 4.10 & 2.00 & 1.87 & 2.00 \\
\hline Palpitations & 5.00 & 4.60 & 2.60 & 3.60 & 3.70 & 3.20 & 3.50 & 3.70 & 2.63 & 2.29 & 2.17 \\
\hline Sweating & 2.60 & 2.80 & 1.10 & 1.10 & 0.80 & 2.20 & 1.00 & 0.90 & 1.23 & 1.44 & 1.10 \\
\hline Dry mouth & 1.60 & 1.80 & 1.80 & 1.60 & 1.40 & 1.60 & 0.70 & 1.10 & 1.00 & 0.91 & 0.79 \\
\hline Dizziness & 4.10 & 4.00 & 2.30 & 2.70 & 2.80 & 2.10 & 1.70 & 2.40 & 1.24 & 1.41 & 1.41 \\
\hline Nauseá & 2.50 & 2.80 & 1.50 & 1.40 & 2.20 & 2.10 & 2.10 & 2.80 & 1.56 & 1.60 & 1.58 \\
\hline Hot flashes & 2.70 & 3.10 & 1.80 & 1.80 & 1.70 & 3.40 & 2.20 & 1.90 & 1.44 & 1.54 & 1.37 \\
\hline Increased urination & 1.90 & 1.60 & 0.60 & 0.60 & 1.70 & 2.80 & 2.90 & 2.00 & 0.34 & 0.90 & 0.21 \\
\hline Trouble swallowing & 0.70 & 0.70 & 0.70 & 0.70 & 0.70 & 1.40 & 0.70 & 1.40 & 1.00 & 0.74 & 0.90 \\
\hline Keyed up & 6.50 & 5.00 & 2.90 & 2.80 & 5.30 & 4.40 & 4.40 & 5.32 & 2.76 & 2.64 & 2.54 \\
\hline Jumpy & 4.90 & 4.40 & 2.50 & 2.10 & 1.70 & 3.70 & 2.10 & 2.50 & 2.09 & 1.47 & 1.40 \\
\hline Difficulty concentrating & 3.90 & 3.90 & 2.70 & 2.60 & 280 & 3.80 & 3.20 & 2.90 & 1.60 & 1.14 & 1.37 \\
\hline Irritability & 7.90 & 5.90 & 3.30 & 3.10 & 3.70 & 4.00 & 3.40 & 4.50 & 2.83 & 1.97 & 1.57 \\
\hline Physical discomfort & 7.50 & 5.20 & 1.30 & 1.90 & 5.20 & 5.30 & 4.10 & 4.40 & 2.64 & 3.09 & 1.81 \\
\hline Mean Score & 4.56 & 3.50 & 1.94 & 2.05 & 3.00 & 3.08 & 2.55 & 2.86 & 1.86 & 1.78 & 1.52 \\
\hline
\end{tabular}

All scores rated $0(=$ 'none') to $9(=$ 'most cver'): $1=$ premenstrual week; 2 = perimenstrual week: and 3 and 4 mid-cycle weeks (the seven days closest to the mid-cycle point for the prospective data: ' 3,4 '). 
toms, rated on the same scale $(0-9)$, retrospective patient ratings indicated greater symptom fluctuation across the menstrual cycle than either daily prospective patient ratings or weekly joint patient-clinician ratings, but the number of symptoms that showed at least a small increase premenstrually was significant.

In addition to the 25 symptoms described above (Table 1 ), other retrospective ratings were significant. Patients rated 'panic attacks' $(P<0.03)$. 'agoraphobic symptoms' $(P<0.006)$, and 'premenstrual symptoms' $(P<0.001)$ all as significantly fluctuating over the cycle, again with the premenstrual/perimenstrual time as highest. Further, nine of the ten subjects retrospectively rated their peak panic and 'tension' severity as having occurred during the premenstrual week. Among the weekly ratings, only intensity of full situational panic attacks fluctuated significantly $(P<$ 0.02 ). No other prospective ratings fluctuated significantly, and patients rated themselves prospectively as under equal levels of 'stress' across the menstrual cycle.

Mean scores for patients diagnosed as having agoraphobia as well as panic attacks were higher on most items than for patients with panic attacks only. Sometimes this difference reached statistical significance (e.g., mean score for all SCL-90-R items, $P<0.002$ ), and sometimes it did not. Overall, it appeared that patients with agoraphobia were more severely affected than those without.

Only one subject, during the post-study 'debriefing', indicated that she thought the purpose of the study was to study menstrual changes in anxiety symptoms. Eight of the ten subjects thought that the month of the study was a symptomatically typical month; one stated that her symptoms were more severe and another stated that they were less severe.

\section{Discussion}

The results of this study agree with prior studies which indicated that women with panic attacks, with or without agoraphobia, believe their anxiety disorder is more severe pre- and/or perimenstrually. However, daily ratings of the identical symptoms, as well as other anxiety ratings. indicate that fluctuations in anxiety symptoms are actually rather small across the menstrual cycle. The discrepancy in results of the two types of ratings is mainly, but not completely, due to higher ratings retrospectively than prospectively in the pre- and perimenstrual portions of the menstrual cycle. Weekly ratings showed intermediate severity, but minimal menstrual fluctuation, despite the fact that the clinician was not blind to the study hypothesis or to the point in the cycle at which the rating was being performed. Post-study 'debriefings' indicated that only one of the patients suspected the specific purpose of the study.

Only ten subjects were evaluated in the study: if more subjects or more cycles had been studied, or if patients had been more severely anxious, the actual differences observed in several symptoms across the cycle might have reached statistical significance (Table 1). Even if this were to occur, however, it seems likely that the discrepancy between retrospective and prospective daily ratings in magnitude of effect would remain. Fluctuations of subjective 'stress' did not appear to play any role in outcome.

There are several possible explanations for the observed results. (a) Were patients more agoraphobic pre/perimenstrually, and did a reduction of daily activity lead to lower daily symptom ratings? Subjects denied this during the debriefing: furthermore, only half of the subjects had agoraphobia of clinically significant severity. (b) Did patients subjectively decrease their prospective symptom ratings in the pre/perimenstruum because they 'expected' them to be higher? Again, results of debricfings indicated that this was not the case. (c) Were the retrospectice pre/perimenstrual ratings increased due to saliency (i.e., were the retrospective ratings done just after menstrual onset, at the end of the rated cycle)? No, retrospective ratings and debriefings were done at variable intervals after completion of the prospective daily ratings.

In contrast to the possible explanations listed above, which do not appear to account for the observed results. two others explanations seem more likely. First, it is possible that the symptoms only show minimal variation (as indicated by the prospective ratings), but that these women have learned from sources other than their own subjective experience to expect more or more severe 
symptoms in the premenstruum; thus, in the retrospective ratings, which are temporally more removed from the actual experience than are the prospective daily ratings, subjects recall their symptoms as more severe at that point in the menstrual cycle. In other words, there is little actual fluctuation in symptomatology, but only an exaggeration due to an error of memory based on inappropriate expectation.

The second explanation is that patients are experiencing some non-specific 'arousal' in the pre/perimenstruum, and that this arousal is different enough from the actual anxiety symptoms that it does not influence the daily ratings, but it is nevertheless salient enough to be recalled and to be mislabeled or misattributed to an exacerbation of anxiety symptomatology at the temporally remote point of retrospective ratings. Several studies have suggested that autonomic arousal does change across the menstrual cycle (Wineman, 1971; Little and Zahn, 1974; Collins et al., 1985; Asso, 1986). Perhaps consistent with this possibility is the fact that the symptoms which fluctuated the most, as rated either retrospectively or prospectively, were not necessarily the symptoms most specific to panic, but were an apparently non-specific mixture of symptoms involving anxiety, irritability, affect change, appetite change, physical discomfort, etc. (Table 1).

It would be premature to conclude that the menstrual cycle does not affect pathological anxiety. Many women (including most of the participants of this study) insist that they are more symptomatic pre- and perimenstrually. Some even claim to need more medication at that time. And some fluctuation, albeit small, did appear to occur. Nevertheless, these results suggest that recall of any fluctuation which does occur is substantially augmented in memory days to weeks later. Furthermore, prior research as well as the results of this study suggest that any symptom fluctuation which does occur might not be of specific anxiety symptoms per se but rather of mood-related or other less specific symptoms such as 'irritability'. In this vein, a study of women presenting to a clinic identified as a 'Premenstrual Syndrome Clinic' found not only an increase in the number of women expected to have a primary anxiety disorder but also an increase in the number of women with an affective disorder or substance abuse (Stout et al., 1986). More research is needed, especially concerning the possibility that women with primary anxiety disorders might be especially prone to menstrual fluctuation of non-specific arousal, since other research has already demonstrated autonomic abnormalities in people with anxiety disorders (Cameron and Nesse, in press).

\section{References}

American Psychiatric Association Committee on Nomenclature and Statistics (1980) Diagnostic and Statistical Manual of Mental Disorders (Third Edition). American Psychiatric Association, Washington, DC.

American Psychiatric Association Work Group to Revise DSM-III (1987) Diagnostic and Statistical Manual of Mental Disorders (Third Edition-Revised). American Psychiatric Association. Washington, DC.

Asso, D. (1986) The relationship between menstrual cycle changes in nervous system activity and psychological, behavioral, and physical variables. Biol. Psychol. 23, 53-64.

Breier, A., Charney, D.L. and Heninger, G.R. (1986) Agoraphobia with panic attacks: development, diagnostic stability, and course of illness. Arch. Gen. Psychiatry 43, $1029-1036$.

Cameron, O.G. and Nesse. R.M. (1988) Systemic hormonal and physiological abnormalities in anxiety disorders: a review. Psycho-Neuroendocrinology (in press).

Cameron, O.G., Lee, M.A., Kotun, J. and Murphy, S.T. (1986) Circadian fluctuations in anxiety disorders. Biol. Psychiatry $21,565-566$.

Collins, A., Eneroth, P. and Landgrin, B.M. (1985) Psychoneuroendocrine stress responses and mood as related to the menstrual cycle. Psychosom. Med. 47, 512-527.

Dalton, K. (1964) The Premenstrual Syndrome. C.C. Thomas, Springfield, IL.

Derogatis, L.R. (1983) SCL-90-R: Administration, Scoring, and Procedures Manual-Il. Clinical Psychometric Research Laboratory, Towson, MD.

Frank. R.T. (1931) The hormonal causes of premenstrual tension. Arch. Neurol. Psychiatry 26, 1053-1057.

Golub. S. (1976) The magnitude of premenstrual anxiety and depression. Psychosom. Med. 38, 4-12.

Hamilton, M. (1959) The assessment of anxiety states by rating. Br. J. Psychol. 32, 50-55.

Harris, R.J. (1975) A Primer of Multivariate Statistics. Academic Press, New York, NY.

Lahmeyer, H.W., Miller, M. and DeLeon-Jones, F. (1982) Anxiety and mood fluctuation during the normal menstrual cycle. Psychosom. Med. 44, 183-194.

Little, B.C. and Zahn, T.P. (1974) Changes in mood and autonomic function during the menstrual cycle. Psychophysiology 11, 579-590.

Marks, I.M. and Mathews, A.M. (1979) Brief standard self-rating for phobic patients. Behav. Res. Ther. 17, 263-267. 
Rubinow. D.R. and Roy-Byrne, P. (1984) Premenstrual syndromes: overvicw from a methodolngical perspective. Am. J. Psychiatry 14, 163 - 172,

Sheehan, D.V. (1986) The Anxiety Disease. (Revised Paperback Edition.) Bantam Books, New York, NY.

Spityer, R.L. and Williams, J.B.W. (1983) Instruction Manual for the Structured Clinical Interview for DSM-III (SCID). Biometrics Research Department. New York State Psychiatric Institute, New York, NY.

Steiner, M., Hasketr, R.F. and Carroll, B.J. (1980) Premenstrual tension syndrome: the development of research diagnostic criteria and new rating scales. Acta Psychiatr. Scand. 62. $177-190$

Stout. A.L., Steege, J.F., Blazer, D.G. and George. I.K. (1986) Comparison of lifetime psychiatric diagnoses in premenstrual syndrome clinic and community samples. J. Nerv. Ment. Dis. 1974, 517522

Van Den Akker, O, and Steptoe, A. (1985) The pattern and prevalence of symptoms during the menstrual cycle. Br. J. Psychialry 147, 164-169.

Veith, J.L., Anderson, J., Slade, S.A.. Thompson, P.. Laugel, G.R. and Getzlab. S. (1984) Plasma $\beta$-endorphin, pain thresholds and anxiety levels across the human menstrual cycle. Physiol. Bchav. 32, 31-34.

Wineman, F.W. (1971) Autonomic balance changes during the human menstrual cycle. Psychophysiology 8, 1-6.

World Health Organization (1983) A prospective multicentre trial of the ovulation method of natural family planning. III. Characteristics of the menstrual cycle and of the fertile phase. Fertil. Steril. 40, 773-778. 